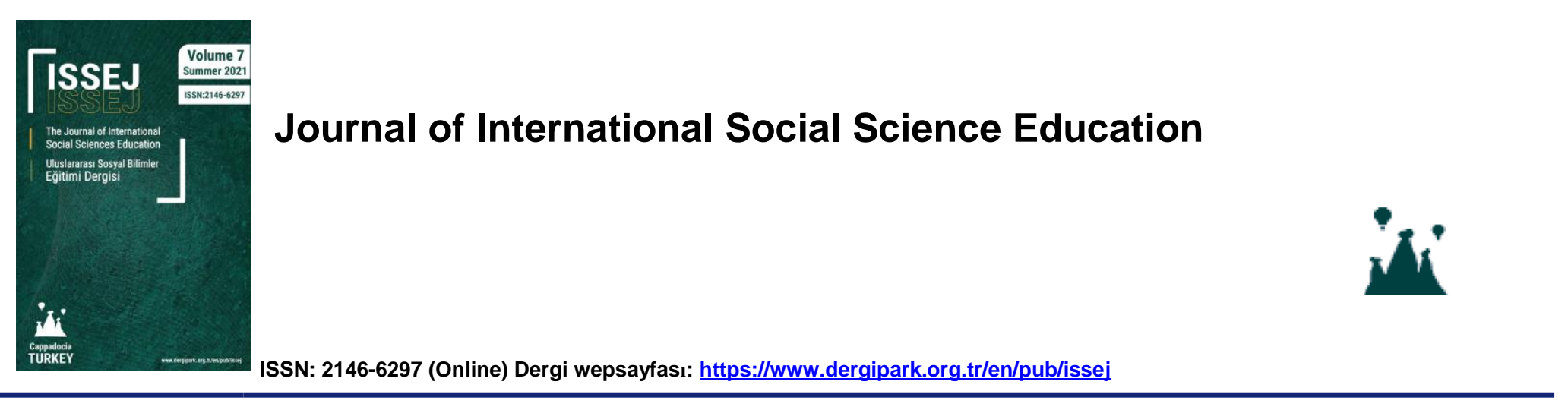

\title{
Kitap değerlendirmesi: Kuramdan uygulamaya sosyobilimsel konular
}

\section{Kadriye Bayram}

Önerilen atıf: Bayram, K. (2021). Kitap değerlendirmesi: Kuramdan uygulamaya sosyobilimsel konular, Uluslararası Sosyal Bilimler Eğitimi Dergisi, 7(1), 200-218. DOI: 10.47615/issej.915640

Makale linki: $\underline{\text { https://doi.org/10.47615/issej.915640 }}$

(อ)

(02020 Yazar(lar). Baskılar ve izinler: Yazarlar makalelerini

USBED/Uluslararası Sosyal Bilimler Eğitimi Dergisinde yayınladıktan sonra basılı olarak veya Birinci Baskı olarak çevrimiçi paylaşma iznine sahiptir.

USBED/Uluşlararası Sosyal Bilimler Eğitimi Dergisi hakemli bir çevrimiçi dergidir. Bu makale araştırma, ögretim ve özẹl çalışmalar amacıyla kullanılabilir. Makalenin içerığinden yanlızça yazarlar sorumludur Dergi makảlelerin telif hakkına sahiptir. Yayıncı, araştırma materyalinin kullanımıyla bağlantılı veya doğrudan veya dolaylı olarak ortaya çıkan herhangi bir kayıp, işlem, talep veya masraf veya zarardan sorumlu tutulamaz.

Tüm yazarlardan, sunulan çalışmalarla ilgili olarak diğer kişi veya kuruluşlarla herhangi bir finansal, kişisel veya diğer ullişkiler dahil olmak üzere herhangi bir fiili veya potansiyel çıkar çatışmasınıı ifşa etmeleri istenir. 


\section{Kitap değerlendirmesi: Kuramdan uygulamaya sosyobilimsel konular}

\section{Kadriye Bayram}

Eğitim Fakültesi, Hacı Bektaş Veli Üniversitesi, Nevşehir, 50300, Türkiye

ÖZ

21. yy becerileri ile bu becerilerin gelişiminde rol alan sosyobilimsel konular (SBK), güncel fen bilimleri öğretim programı ve öğretmen yetiştirme programında doğrudan yer almaktadır. İşlevsel bilim okuryazarlığı ile üst düzey bilgi ve becerilerin gelişimi üzerindeki potansiyel katkıları dikkate alındığında, SBK'nın eğitime etkin entegrasyon süreci teoride ve uygulamada önem arz etmektedir. Dolayısıyla bu çalışmada, SBK'nın fen eğitimindeki yeri ile SBK öğretimi üzerine yapılandırılan "Kuramdan Uygulamaya Sosyobilimsel Konular" adlı kitap; içerik, kapsam, alana sağladığı katkı ve sunduğu öneriler bakımından incelenmiştir. Doç. Dr. Murat Genç editörlügünde, basılı ve e-kitap olarak yayınlanan kitabın hedef kitlesi, fen eğitiminde rol alan öğretmen, öğretmen adayı, akademisyen ve arastırmacılardır. Kitabın bölüm içerikleri, okuyucuya hem SBK hakkında teorik bilimsel bilgi edinme, hem de sınıf içi ve okul dışı öğrenme ortamlarında SBK öğretimine özgü geliștirilen etkinlik örnekleri ve önerileri ile SBK bağlamında fen eğitimini destekleme, deneyimleme ve farklı bakıs açları kazanma fırsatı sunmaktadır. Kitabın yeni basımı için, "SBK'ya özgü pedagojik alan bilgisi, farklı disiplinlere yönelik SBK eğitimi, SBK'ya özgü dijital eğitim materyallerinin geliştirilmesi" gibi yeni bölüm başlıklarının eklenmesi önerilebilir.

MAKALE TARIHI

Gelis tarihi 14 Nisan 2021

Kabul tarihi 17 Haziran 2021

ANAHTAR KELIMELER

Kitap incelemesi, sosyobilimsel konular, fen eğitimi.

Makale Türü

Kitap incelemes 
Kitap Değerlendirmesi

İncelenen Kitap Adı: Kuramdan Uygulamaya Sosyobilimsel Konular

Editör: Doç. Dr. Murat GENÇ

Yayınevi: Nobel Akademik

Basım yılı: Mayıs, 2020

Sayfa say1s1: 440

ISBN: 978-625-402-058-2

21. yüzyılda bilgi toplumunda meydana gelen yeni gelişmeler, toplum yaşamına olumlu ve olumsuz şekilde yansımaktadır (Aydın ve Kılıç Mocan, 2019). Bilim ve teknolojideki yeni gelişmeler, toplumun ikilem oluşturan konularla karşılaşarak konu ile ilgili karar vermelerini gerektirmektedir (Kutluca 2012). Nitekim günümüzde küresel Covid-19 pandemisi, bireysel ve toplumsal olarak yaşantımızın her alanını etkilemektedir. Bu etkiler, başta sağlık ve ekonomi olmak üzere, eğitim alanında da hissedilmektedir. Dolayısıyla sosyobilimsel konular, eğitim sürecinde önemi artan yaklaşımlardan biri haline gelmiştir. Çünkü pandemi ile birlikte toplum üyeleri, tartışmalı ve risk yönetimi gerektiren çeşitli sosyobilimsel durumla karşı karşıya kalmıştır. Tartışmalarla ortaya çıkan bu durumlar, fen eğitiminde sosyobilimsel konu (SBK) olarak nitelendirilmektedir (Evren Yapıcıŏlu, 2020). Alanyazında SBK, bilimle ilişkili, toplumu ilgilendiren, kesin çözümü olmayan, açık uçlu problemler (Sadler, 2004, 2011; Sadler ve Zeidler, 2005) olarak tanımlanmaktadır. Aynı zamanda SBK, bu karmaşık problemleri fen öğretimi bağlamlarında kullandırmaya olanak tanıyan bir fen eğitimi temasıdır (Sadler, 2011). Öğrencileri bu temaya dahil etmenin, bilimsel okuryazarlığı teşvik etmede etkili olduğu belirlenmiştir (Zeidler, 2014). Çünkü SBK üzerine tartışma ve muhakeme yapma, bilimsel okuryazarlığın ayrılmaz parçasıdır (Sadler ve Zeidler, 2004). Aynı zamanda SBK, öğrencilerde işlevsel bilimsel okuryazarlığın desteklenmesi ile ilgili birçok alana ivme kazandırmakta olup, öğrencilerin bilgiye dayalı karar vermelerini, veri kaynaklarını analiz etme, sentezleme ve değerlendirmelerini, etik konularda ahlaki muhakemeye katılmalarını ve bağlama dayalı fen öğrenmede kurulan ilişkilerin karmaşık yapısını anlamalarını gerektirmektedir (Zeidler, Herman ve Sadler, 2019). Tüm bu etki ve katkıları dikkate alındığında, gerçek yaşamdaki sosyobilimsel durumları farkeden, yerel ve küresel sorunlarla başetmede bilimi etkin kullanan, geleceğin bilinçli ve duyarlı aktif vatandaşlarını yetiştirme ihtiyacı doğmaktadır (Evren Yapıcıŏlu, 2020; Ke, vd. 2020). Bu hedefin gerçekleşmesinde, eğitim paydaşlarının SBK'nın doğası ile SBK öğretimini net bir şekilde anlaması ve sınıf içi, okul dışı öğrenme ortamlarında SBK bağlamlı etkinlikleri etkin şekilde uygulaması son derece önemlidir. Dolayısıyla bu sürece rehberlik eden güncel başucu kitapların okuyuculara tanıtılması, "içerik ve kapsam" bakımından incelenmesi yerinde görülmektedir.

Alanyazında "yükseköğretim (Nasır, 2011; Saruç, 2018), öğretmen yetiştirme süreci (Yaman, 2018), fen eğitimi" üzerine gerçekleştirilen kitap değerlendirmesi çalışmalarına ulaşmak mümkündür. Fen eğitimi alanındaki güncel kitap değerlendirmesi çalışmaları dikkate alındığında, "kuramdan uygulamaya STEM eğitimi" (Özgün ve Özgün, 2019) ile "fen bilgisi öğretmenlerinin pedagojik alan bilgilerini anlama ve geliştirme" (Küçükaydın ve Uluçınar Sağır, 2016) başlıklarındaki kitapların incelendiği tespit edilmiştir. Bu çalışmaların, ulusal ve uluslararası kitapları "kapsam ve içerik" yönünden ele aldığı, "alana sağladığı katkı ve sorunlara getirdiği pratik çözüm önerilerini”" inceleyerek okuyucuya sunduğu, farklı konular ile hedef gruplar için verilen pratik bilgi ve yeni nesil örnek ders planlarını vurgulayarak tanıttığ 1 , buradan hareketle konunun "kuramı ile uygulaması" arasındaki ilişkinin önemine dikkat çektiği sonucuna ulaşılmaktadır. Dolayısıyla bu çalışmada, günlük yaşamımızda önem arz eden sosyobilimsel konuların fen eğitimindeki yeri ile SBK öğretimi üzerine yapılandırılan güncel bir kitabın, "içerik, kapsam, sunduğu firsatlar ve öneriler" bakımından detaylı incelenmesi amaçlanmıştır. SBK'ya özgü farklı konu içeriklerini tek kaynakta sunan bu kitabın incelenmesi ile, okuyucunun her tema hakkında anlayış kazanması beklenmekte olup, bu yönüyle çalışma önem arz etmektedir.

Bu çalışmada, Doç. Dr. Murat GENÇ editörlüğünde hazırlanan "Kuramdan Uygulamaya Sosyobilimsel Konular" isimli kitabın, 2020 yıll, Mayıs ayında yayınlanan birinci basımına ait bir değerlendirmesi gerçekleştirilmiştir. Basılı ve e-kitap olarak yayınlanan bu kitap, xviii+422 sayfadan ve 16 farklı bölümden oluşmaktadır. Kitabın hedef kitlesi, fen öğretiminde rol alan öğretmen, öğretmen adayı, akademisyen ve araştırmacılardır. Kitabın bölüm içerikleri, alanında uzman 20 araştırmacı tarafından yapılandırılmıştır. İçeriğin "sarmal bir yapıda", disiplinlerarası bakış açısıyla oluşturulduğu dikkat çekmektedir. Sosyobilimsel konular üzerine basılmış ulusal ve uluslararası kitapların sürdürülebilirliğini artırıcı ve ivme kazandırıcı nitelikteki bu kitap ile, konu kapsamının çeşitlendirildiği, 
alternatif ek başlıkların ele alındığı, çok sayıda etkinlik örnekleri ile teorik konunun uygulamadaki yansımalarının daha detaylı ve derinlemesine incelendiği anlaşılmaktadır. Konularına göre kitabın bölüm başlıkları şu şekildedir: "Sosyobilimsel konular (SBK) ile bilim-tutum ilişkisi, SBK doğası ve fen eğitimindeki yeri, SBK ile fen öğretimi ve değerlendirme, $S B K$ seçimi ve güncel ikilem örnekleri, $S B K$ ve ögretim stratejileri, SBK ve argümantasyon, $S B K$ ögretiminde SEE-SEP modeli, SBK'da muhakeme, Sosyobilimsel muhakemenin değerlendirilmesi, SBK ve soru üretme muhakemesi, SBK ögretiminde medyanın rolü, SBK'da etik, SBK ve okul dişı ögrenme ortamlarl, epistemolojik inançlar ve SBK, SBK öğretiminde ögretmen rolleri ve mentorluk, SBK ve STEM eğitimi”.

Yalın ve akıcı akademik dilde yazılan kitabın her bir bölümü SBK bağlamında ele alınmış olup, ilk olarak içeriğe ait bölüm kazanımları belirtilmiştir. Akabinde, içeriğin genel çerçevesi tanıtılarak, konunun detaylı kavramsal yapısı betimlenmiş, içerikle ilişkili değişkenler alanyazın desteğiyle tanımlanarak derinlemesine açılanmıştır. Tablo, resim, şema, model ve şekillerle konuya özgü çeşitli gösterimler kullanılmıştır. Ardından, içerik kazanımları ile uyumlu SBK’ya özgü etkinlik örnekleri sunulmuştur. Buna ek olarak, konunun doğası kaynaklı eleştiriye ve sorgulamaya açık kritik durumlar vurgulanmış, içerikle ilgili sonuç ve çıkarımlarda bulunulmuştur. Bölüm sonunda ise açık uçlu ve çoktan seçmeli maddelerden oluşan bölüm değerlendirme sorularına yer verilmiştir. Kitabın her bölümünde ortak bulunan başlıkların "bölüm kazanımları", "giriş" ve "bölüm değerlendirme soruları" olduğu dikkat çekmektedir. Bu kapsamda kitabın her bir bölümüne ait değerlendirme raporu aşağıda sunulmuştur.

İlk bölüm editör tarafindan yazılmış olup, bu bölümde sosyobilimsel konular ile bilim-tutum ve bilimsel okuryazarlık arasındaki ilişki incelenmiştir. İçerikte, sosyobilimsel konuların (SBK) kavramsal çerçevesi ve tanımı yapılarak, siklıkla gündemde olan global boyuttaki SBK örneklerine yer verilmiştir. Tutum ve bilimsel tutum kavramlarından bahsedilmiş, bilgi ve inancın tutuma yön vererek, kişisel değer ve dünya görüşlerine yansıdığı vurgulanmıştır. $\mathrm{Bu}$ ifade, "tutumla ilgili fikirlerin olası analizleri" başlığında şekil üzerinde modellenmiştir. Bilimsel tutumun boyutları (rasyonellik, tarafsızlık, bilimsellik, vb.), bileşenleri (inanç, his, eylem) ile bilimsel tutuma sahip bireyin özelliklerine (nesnellik, açık fikirlilik, yaratıcılık, vb.) yer verilmiştir. Akabinde, global ikilemli konulardan yerel/bölgesel konulara, geniş ölçekte günlük yaşantımızda yer alan "sosyobilimsel konular hakkında karar verme" üzerinde "bilim, tutum, teknoloji ve toplum" etkisinden bahsedilmiştir. Aynı zamanda, SBK destekli öğrenme ortamları ile bireylerin duyuşsal, sosyal ve bilişsel gelişimi, muhakeme ve karar verme yeteneği üzerinde çeşitli faktörlerin etkisine dikkat çekilmiştir. Bu kapsamda, bilimsel tutumları farklı düzeyde olan öğrencilerin eğitim süreçlerinin SBK ile desteklenmesi önerilmiştir.

İkinci bölüm, sosyobilimsel konuların (SBK) özellikleri ile doğası, SBK örnekleri, dünyada ve ülkemizde SBK'nın tarihsel süreci, fen bilimleri programlarındaki yeri, SBK öğretiminin önemi, SBK ile ilişkilendirilen temel fen kazanımları temalarında yapılandırılmıştır. İlk olarak bölümde, toplumsal tartışmalı konuların nasıl gündeme geldiği vurgulanmış, alanyazından SBK tanımına ve özelliklerine yer verilmiştir. SBK ile ilgili karar verme sürecine etki eden etmenler belirtilmiştir. Bu etmenler arasında, deneyim, sosyal-duygusal etmenler, etik değerler vurgulanmıştır. SBK öğretiminin tarihsel gelişimi bağlamında, dünyada izlenen farklı fen öğretimi programı yaklaşımları, eksik ve olumlu yönleri ile eleştirel bakış açısıyla incelenmiştir. SBK öğretiminin, fen-teknolojitoplum (FTT) ve fen-teknoloji-toplum-çevre (FTTÇ) yaklaşımlarından farklı olan özelliklerine değinilmiştir. SBK öğretiminin gerekliliklerinden hareketle, SBK temelli fen öğretimi ile "bilimsel okuryazarlık, bilimin doğası anlayışı, muhakeme becerileri ve fen konu alan bilgisinin" incelendiği araştırma sonuçlarına yer verilmiştir. Aynı zamanda muhakeme türlerinden "formal, informal ve sosyobilimsel muhakeme" arasındaki farklar model üzerinde gösterilmiştir. Ayrıca ülkemizdeki fen bilimleri, fizik, kimya ve biyoloji öğretim programlarında SBK'nın yeri ve önemi tarihsel olarak incelenmiştir. Benzer şekilde, dünya ülkelerinde SBK'nın öğretim programına entegrasyon süreci açıklanmıştır. Öğretim programında SBK'nın etkili kullanılmasında öğretmen, öğretim materyalleri gibi çeşitli değişkenlerin önemine dikkat çekilmiştir. Ardından, SBK öğretimine yönelik örnek etkinlik planına yer verilmişstir.

SBK tanımıyla başlayan üçüncü bölümde, SBK'nın tartışmalı ve karmaşık olma gerekçelerine değinilmiştir. Buradan hareketle, alternatif olanakları sunması bakımından SBK'nın fen öğretiminde kullanılması gereği vurgulanmıştır. SBK'nın eğitime entegrasyonu, fen, fizik ve biyoloji öğretim programlarındaki kazanımları ile açıklanmıştır. Bir konunun SBK olarak belirlenme ölçütleri ile SBK kaynakları gösterilmiştir. Sınıf ortamında SBK bağlamında fen öğretimi için izlenecek adımlar belirtilmiştir. Yerel ve küresel boyuttaki SBK'nın dengeli şekilde öğretim sürecine entegrasyonunun sağlanması gerektiği vurgulanmıştır. Bu bağlamda, SBK materyallerinin özelliklerine, öğretim çıktılarını etkileyen öğretmen-öğrenci etkileşimine, öğretmenin süreçteki rollerine kısaca değinilmiştir. İnsan ve Çevre konusunda 5E modeline dayalı örnek öğretim yapılandırması etkinliği sunulmuştur. Ardından, SBK tabanlı fen öğretimi öncesinde, süreçte ve sonrasında, öğrenilenleri günlük yaşamda kullanma firsatı sunan değerlendirme türleri ile etkinlikler önerilmiştir. SBK tabanlı bilgi ve becerilerin ölçmedeğerlendirilmesindeki güçlüklere dikkat çekilmiştir. SBK tabanlı kavramsal öğrenme düzeyi, bilimsel düşünme ve 
karar verme becerisi ile bilimin doğası anlayışının farklı ölçme araçları ile değerlendirildiği, alanyazından örnekleriyle açıklanmıştır. Bu kapsamda model-kanıt ilişkisi şeması tanıtılmıştır.

Dördüncü bölümde, sosyobilimsel konuların (SBK) seçim yollarına, SBK seçiminde etkili olan değişkenlere, SBK senaryo yazımına ve örnek güncel sosyobilimsel ikilemlere yer verilmiştir. Öncelikle konu seçimi için SBK ve özellikleri tanımlanmıştır. Fen eğitiminde alanyazında sıklıkla çalışılan yerel, ulusal ve global SBK örneklerine yer verilmiş, bu konuların öğretim programındaki yeri ile ilişkili olduğu içerik ve kavramlar detaylı belirtilmiştir. Bu kapsamda çalışmalarda programa entegre edilen bazı SBK örneklerinin bilimsel bağlamı, hedef sistemi ve içerikleri şekil üzerinde özetlenmiştir. Uygun bir SBK seçim yolu şema ile gösterilmiştir. SBK değerlendirilmesinde farklı araştırmacıların önerdiği birbiriyle örtüşen çeşitli ölçütler sunulmuştur. Bu ölçütler, "bilimsel ve toplumsal boyut, ikilemli ve tartışmaya açık yapı, ekonomik-etik-politik bakış açısı vb." olarak belirtilmiştir. Bu bölümde ayrıca, SBK senaryolarının yazımında dikkat edilmesi gereken hususlar bağlamında genel çerçeve oluşturulmuştur. Bölüm yazarı tarafından, farklı SBK için ünite tasarımı yapılabileceği önerilmiştir.

Sosyobilimsel konularda öğretim stratejileri üzerine yapılandırılan beşinci bölümde ilk olarak bilişsel, sosyal, ahlaki ve duygusal becerilerin gelişmesinde SBK öğretiminin önemli olduğu vurgusu yapılmıştır. SBK'da öncelikli kazandırılması gereken becerilere dikkat çekilmiştir. MEB programlarında yeri belirtilen SBK'nın öğretim stratejilerine odaklanılmıştır. Bu kapsamda, SBK aktivitelerinde sıklıkla münazara, rol oynama yöntemlerinin kullanıldığı belirtilmiş, küçük grup tartışmaların uygunluğuna değinilmiştir. Ayrıca alanyazında yer alan SBK öğretim modelleri açıklanmıştır. Bu modelleri, sözel/yazılı, görsel ve çoklu uyarıcıların desteklediği belirtilmiştir. Buradan hareketle SBK öğretiminde uygun araç, yöntem ve teknikten yararlanılmasının öğrenme çıtıları üzerinde etkili olduğu vurgulanmıştır. Farklı yöntemlerin kullanılmasında, SBK içerik bilgisine dikkat çekilmiştir. Konuya yönelik alternatif yöntemlerin kullanıldığ 1 örnek etkinliklere yer verilmiştir. Alanyazında SBK için önerilen pedagojik model açıklanmıştır. Akabinde SBK öğretiminde farklı stratejilerin kullanılması için dikkat edilmesi gereken hususlar belirtilmiştir. Sosyobilimsel içerikli ders oluşturma süreci maddeler halinde verilmiş olup, "beslenme" konusunda detaylı bir etkinlik planı sunulmuştur.

Altıncı bölüm, sosyobilimsel konularda argümantasyon temasında olup, bölümde ilk olarak, üst düzey becerilerin gelişimi için SBK temelli öğretim vurgulanmıştır. "SBK yaklaşımı ile sorgulama temelli yaklaşım" ve "karar verme ile görüş geliştirme" arasındaki farklara değinilmiş, "GDO, su kaynağı ve ormansızlaşma" konuları ile örneklendirilmiştir. SBK temelli öğretimle çeşitli becerilerin geliştirilmesi sürecinde öğretmen rolleri belirtilmiştir. Bu kapsamda alanyazında sıklıkla kullanılan argüman modelleri tanıtılmış, uygulama örneklerine yer verilmiştir. Akabinde iklim değişimi konusu üzerinden "bilimsel açıklama ile argümantasyon" kavramları arasındaki farka odaklanılmışıır. Argümantasyon teknikleri tanıtılmış, her bir teknik fen konuları ile örneklendirilmiş̧ir. Son olarak argümantasyon becerilerinin değerlendirilmesine yer verilmiştir. Bu kapsamda, SBK'ya özgü geliştirilen metin ve kanıta dayalı değerlendirme şeması ile rubrik tanıtılmıştır. Bölüm yazarı tarafından, bu tür öğretim ve ölçme araçlarının farklı SBK için kullanılabileceği önerilmiştir.

Sosyobilimsel konular ile içeriğinin detaylı tanıtılmasını takiben yedinci bölümde, SBK'da karar verme becerilerinin gelişimi ve karar verme sürecinin analizine yönelik alanyazında önerilen SEE-SEP modeli, örnekler üzerinden tanıtılmışırı. SEE-SEP modeli ve modelde yer alan farklı disiplinlerle boyutların etkileşimi, şekil ile gösterilmiştir. Alanyazında bu modelin kullanılma alanları, "karar verme ve kararı destekleme sürecini etkileyen etmenlerin belirlenmesi" olarak belirtilmiştir. Bu model çerçevesinde, SBK karar verme sürecinde altı disiplinin bütüncül ele alındığı ve bu disiplinlerin üç farklı boyutla etkileşim halinde olduğu betimlenmiştir. Modelde oluşan disiplin-boyut etkileşimleri, örnek sosyobilimsel iddialarla bir tablo üzerinde gösterilmiş, örnek senaryolarla açılanmıştır. Buradan, sosyobilimsel konu bağlamının, etkileşimin yönünü etkilediği sonucuna örnekler üzerinden ulaşılmıştır. Bu bölümde, sosyobilimsel konularda bilinçli karar verme becerilerinin, argümantasyon ve bilimsel okuryazarlık için önemi vurgulanmıştır. Bölüm sonunda, öğretmen adaylarının "genetik ve biyoteknoloji" konusuna yönelik karar verme becerilerini geliştirmek ve süreci etkileyen faktörleri belirlemek üzere senaryo destekli bir öğretim planının sınıf ortamındaki uygulama örneği gösterilmiştir.

Sekizinci bölümde, SBK temelli fen öğretimi ile çeşitli "muhakeme" süreçlerine yer verilmiştir. Alanyazından tanımı yapılan "muhakemenin" türleri açılanmış, bilişsel, duyuşsal ve sosyal faktörlerden etkilendiği belirtilmiştir. Alanyazından, SBK için çeşitli muhakeme örüntüleri gösterilmiş̧ir. Örüntülerin, içerik ve bağlama göre değişebileceği örneklerle açıklanmıştır. Ayrıca sosyobilimsel muhakemenin tanımı yapılarak, çeşitli konular üzerinden sosyobilimsel muhakemenin boyutları açıklanmıştır. Bunlara ek olarak, fen okuryazarı bireylerin yetiştirilmesi sürecinde muhakeme yapma yeteneğin geliştirilmesinin önemli olduğu vurgulanmıştır. Güncellenen fen bilgisi öğretmenliği lisans programına eklenen yeni derslerin, muhakeme süreçlerine yapılan önemin yansıması olarak değerlendirilmiştir. Başarılı bir muhakeme süreci ve SBK temelli öğretim üzerinde etkili olan faktörler 
(öğretmen, bağlam, vb.) belirtilmiştir. Bölüm sonunda fen bilimleri derslerinde kullanılabilecek, organ nakli konusunda örnek bir uygulama etkinliği sunulmuştur.

Dokuzuncu bölümde, sosyobilimsel muhakemenin değerlendirilmesine yönelik farklı yaklaşımlar ile ölçme araçları hakkında teorik ve pratik bilgiler verilmiştir. Sosyobilimsel muhakeme çalışmalarında sıklıkla odaklanılan temalar (tutum, beceri, vb.) belirtilmiştir. Sosyobilimsel muhakeme becerisinin değerlendirilmesi için geçmişten günümüze farklı kademelerde kullanılan, nitel ve nicel ölçme araçlarına (görüşme, anket, vb.) yer verilmiştir. Aynı zamanda alanyazındaki örnekleri gösterilerek, ölçme araçlarının farklı konular için uyarlanmış halinin kullanılabileceğine dikkat çekilmiştir. Akabinde, sosyobilimsel muhakemenin, nicel ve nitel yaklaşımla değerlendirilmesinin olumlu ve olumsuz yönleri açıklanmıştır. Değerlendirme yaklaşımlarından kaynaklı farklı sınırlılıkların giderilmesi için alternatif öneriler sunulmuştur. Sosyobilimsel muhakemenin daha derinlemesine değerlendirilmesi için, iki farklı ölçme aracının birleştirilmesi ile alternatif değerlendirmenin sağlanabileceği alanyazından örneği ile gösterilmiştir.

10. bölümde, üst düzey düşünme için SBK'ya yönelik derin soru üretme muhakemesi başlığı ele alınmıştır. İlk olarak, Vygotsky'nin öğrenme kuramı tanıtılmıştır. Ardından, diyalojik öğretim ile geleneksel monolojik yöntemin farklarına değinilmiş, her içerikte diyalojik öğretimin zorluğundan hareketle, soru üretme ve soru sorma becerilerinin önemine değinilmiştir. Ayrıca, soru kalitesini ve soru sormayı etkileyen faktörler belirtilmiştir. Bu kapsamda, üst düzey düşünme becerilerini destekleyen derin soruların önemi vurgulanmıştır. Eğitimde, düşük düzeyden ileri düzeye doğru muhakeme modellerine örneklerle dikkat çekilmiştir. Soru sorma ve diyalog üzerine öğretmenlerin pedagojik alan bilgisinin gelişimini inceleyen alanyazından çalışmalara yer verilmiştir. Bunlara ek olarak bölümde, soru üretmeye etki eden faktörler ve soru üretme yollarına yer verilmiştir. Metin/senaryo temelli soru üretmenin, çeşitli öğrenci yeterlikleri üzerindeki etkileri belirtilmiştir. Bu yeterliklerin gelişimine yönelik bölüm sonunda, SBK öğretiminde argümantasyon tabanlı derin soru üretme ile ilgili etkinlik örneği sunulmuştur.

11. bölüm, SBK öğretiminde medyanın rolü başlığında olup, son yıllarda sosyobilimsel konu içeriklerine medyada daha fazla yer verildiğine dikkat çekilmiştir. Bu kapsamda medya ve bilim okuryazarlık kavramlarına aynı anda vurgu yapılmıştır. SBK tanımına yer verilmiş, geçmişten günümüze fen bilimleri öğretim programlarındaki SBK kazanımları ile fen-teknoloji-toplum (FTT) yaklaşımından, sosyobilimsel durum temelli öğretim yaklaşımına geçiş süreci açıklanmıştır. SBK'nın fen eğitimi ve toplum açısından önemine yer verilmiştir. SBK'nın altı konu alanının, üç bileşenle ilişkili olduğunu gösteren SEE-SEP modeli, bu bölümde "SBK yapısı" olarak açılanmıştır. Fen konularıyla sosyobilimsel konular arasındaki farklara değinilmiş, SBK özellikleri ve SBK bilgi kaynakları arasında medyaya dikkat çekilerek, medya konusu detaylı ele alınmıştır. Bu kapsamda ilk olarak medya tanımına yer verilmiş, etkileşim özelliği bakımından medya türleri belirtilmiştir. Akabinde, medyanın bilgi akışı sağlamadaki rolü, düşünce yapısına etkisi, bilim ve toplumla olan ilişkisi açıklanmıştır. Ayrıca bilinçli medya kullanımının öneminden hareketle medya okuryazarlı̆ğ, tarihçesi, öğretim programlarındaki yeri ile bireye kazandırdığ beceriler ve değerlere yer verilmiş̧ir. Ardından, SBK'ya yönelik medyadaki bilim haberlerinin niteliği, içeriği ile nasıl okunması gerektiği hususlarına dikkat çekilmiştir. Eğitim aracı olarak SBK öğretiminde medyanın önemi vurgulanmıştır. Bu kapsamda, medya okuryazarlığı içeriği ile SBK eğitimi entegrasyonunun sağlanması gereği önerilmiştir.

12. bölüm SBK'da etik ve ahlak bağlamında yapılandırılmıştır. Girişte, etik ve ahlaki sorgulamaların önemine değinilmiştir. Alanyazından, işlevsel fen okuryazarlığının sosyobilimsel ögeleri, bir model üzerinde gösterilmiştir. Etik boyutuyla gerçekleştirilen SBK öğretiminin, ahlaki muhakeme, anlamlı öğrenme vb. değişkenler üzerindeki olumlu etkileri sonucuna ulaşılmıştır. Bölümde ayrıca etik kavramı, etik türleri, etik ve ahlak arası farklar, ahlaki yargı gelişimi ve etik eğitimi temalarına yer verilmiş̧ir. İlk olarak, ahlak felsefesi disiplini altında "etik" teriminin kökeni incelenerek tanımı yapılmıştır. Etiğin amaçları ile temel sorunları ele alınmıştır. Ahlak ve etik kavramların kökeni incelenmiş, tanımları karşılaştırmalı yapılmış, alanyazın desteğiyle farkı belirtilmiştir. Etik türleri açılanmış, çeşitli çalışma alanlarına yer verilmiştir. Bu etik türlerinin, hangi problemlere çözüm önerileri sunduğu açıklanmıştır. Ayrıca bağlam, disiplinlerarası bütüncül yaklaşım ve vaka araştırması bakımından etik türlerinin farklarına değinilmiştir. Etikte, yargıların haklılığını temellendiren çeşitli argümantasyon biçimlerine yer verilmiştir. Ahlak ve etik bağlamında çeşitli becerilerin gelişimi için "etik eğitimi" ve "etik eğitiminde SBK"nın önemi vurgulanmıştır. Sosyobilimsel konularda etik eğitimi kapsamında, özel gelişim alanına özgü değerlendirme araçlarına yer verilmiştir.

SBK ve okul dışı öğrenme ortamları içeriğinde yapılandırılan 13. bölümde, bilgi, beceri ile bilim okuryazarlığın gerçekleştirilmesinde alternatif öğrenme ortamların önemi vurgulanmıştır. Ayrıca, verilen örnek etkinliklerle, farklı okul dışı öğrenme ortamlarının SBK öğretimi sürecindeki etkililiğine vurgu yapılmıştır. Girişte, bilimsel okuryazarlık kavramı ve alt boyutlarına değinilmiştir. Ardından, SBK literatürüne dayalı bibliometrik analizden hareketle, okul dışı öğrenme ortamlarına entegre edilen SBK'nın önemi vurgulanmıştır. Alanyazında, okul dış1 
ortamlarda gerçekleştirilen SBK çalışmaları ve incelenen değişkenler belirtilmiştir. Okul dışı öğrenme ortamlarından alan gezilerine örnekler gösterilmiştir. Bu kapsamda, "tarımda kimyasal kullanımı" konusunda alan gezisi etkinlik örneği sunulmuştur. Bir diğer okul dışı öğrenme ortamı olan bilim merkezleri ile SBK öğretimindeki rolüne değinilmiştir. Bu bağlamda, "enerji kaynakları" konusunda gerçekleştirilen bir etkinlik örneğine yer verilmiştir.

14. bölümde ilk olarak fen okuryazarlığı vizyonundan hareketle SBK'nın gerekliliği vurgulanmıştır. Ardından, "epistemolojik inançlar" kavramı tanıtılmıştır. Alanyazından, farklı yaklaşımlara dayalı epistemoloji hakkındaki görüşler açıklanmıştır. İnançlar ve epistemolojik inançların özellikleri belirtilmiş, epistemolojik inanç modelleri çeşitli yaklaşımlarla açıklanmıştır. Epistemolojik inanç ve SBK üzerine yapılan araştırma sonuçları ile epistemolojik inanç ve SBK'nın doğası karşıllaştırmalı incelenmiştir. Buradan hareketle, farklı epistemolojik inançlara sahip öğrencilerin, SBK'ya yönelik bakış açıları örnekler üzerinden incelenmiş, "bilişsel işlem modeli" ile açıklanmıştır. Bölüm sonunda, fen bilimleri öğretim programında (2018) yer alan SBK ile ilgili özel amaçlara yer verilmiş, bu amaçların gerçekleştirilmesinde öğretmenlere öneriler sunulmuştur.

15. bölüm, SBK öğretiminde öğretmen rolleri ve mentorlük başlı̆̆1 ile gerekçelendirilmiştir. Bölümde; SBK öğretiminde öğretmen rolleri, SBK öğretimini etkileyen faktörler, SBK'ya yönelik öğretmenin mesleki gelişimi ve mentorlüğün rolü temalarına yer verilmiştir. Alanyazından, SBK ile ilgili öğrenci kazanımları belirtilmiştir. SBK etkililiğini inceleyen araştırmalardan, SBK ile bilim okuryazar bireylerin yetiştirilmesinin amaçlandığ vurgulanmıştır. Ülkemizde fen programlarında bulunmasına rağmen, sınıf ortamında SBK'nın sınırlı kullanılmasının gerekçelerine değinilmiştir. Bu bağlamda SBK öğretimi çerçevesinde öğretmen nitelikleri belirtilmiş, aynı zamanda, öğretmenin SBK ile ilgili profilleri açıklanmıştır. Bu bölümde ayrıca, SBK öğretimini etkileyen duyuşssal özellikler belirtilmiştir. SBK öğretimini etkileyen diğer faktör altında ise, öğretmenin alan ve pedagojik alan bilgisi açıklanmıştır. Bu kapsamda, SBK tabanlı öğretim uygulamasında öğretmenlerin yaşadıkları zorluklardan bahsedilerek, yaşanan bu zorlukların giderilmesi için çeşitli önerilerde bulunulmuştur. Öğretmenin SBK öğretimindeki rolünün, mesleki gelişiminden etkilendiği sonucundan hareketle, öğretim programlarına tartışmalı konuların doğrudan entegresi önerilmiştir. SBK'ya yönelik öğretmenlerin rolleri ve görevlerinin gelişiminde mentorlük desteğinin önemine dikkat çekilmiştir. Mentorlük desteğiyle, öğretmen yetkinliklerine ek olarak okul ve öğrencilere de olumlu katkı sağlanacağı vurgulanmıştır.

Kitabın son bölümünde, sosyobilimsel konu temelli öğretim yaklaşımı ve STEM eğitimi yaklaşımı ele alınmıştır. STEM eğitimine yönelik tanımlayıcı kavramsal çerçeve sunan bölüm yazarları, fen eğitimi amacından hareketle STEM okuryazarlığ ile fen okuryazarlığı bileşenlerine değinerek, aralarındaki farkı resmetmişlerdir. STEM eğitim reformunun gereklilikleri vurgulanmıştır. K-12 eğitiminde STEM entegrasyonun çerçevesi, alanyazından bir model üzerinde sunulmuştur. Bu çerçevede, STEM okuryazarlığını destekleyici 21. yy. yeterliliklerine değinilmiştir. STEM ve STEAM eğitiminin, öğretim programlarına entegrasyonunda kullanılan yaklaşımların farklı olduğuna dikkat çekilmiştir. STEM eğitiminin doğuşu ve gereklilikleri belirtilmiştir. STEM eğitimiyle ilgili alan eleştirilerine detaylı yer verilmiştir. STEM eğitiminde geliştirilmeye açık bu eleştiriler çerçevesinde, STEM eğitiminde SBK'nın entegrasyonu açıklanmıştır. Bölüm sonunda yazarlar, STEM eğitimine yerel bir sosyobilimsel konuyu entegre ederek uyguladıkları örnek etkinliği sunmuştur.

Kitap genel hatlarıyla incelendiğinde, hemen hemen her bölümde, "SBK'nın tanımı, kapsamı, bilim-teknolojitoplum ile ilişkisi, fen eğitimindeki yeri, SBK öğretimi, bilimsel okuryazarlık" temalarına vurgu yapıldığ anlaşılmaktadır. Hemen her bölümde SBK tanımı, özellikleri ile fen eğitimindeki yeri gibi temalara yer verilmesi, okuyucuyu tekrara düşürme bakımından sınırlılık oluşturabilmektedir. Kitap, çeşitli alt konu başlıkları ile zengin bir içeriğe sahiptir. Kitapta, pedagojik alan bilgisi bileşenleriyle uyumlu olarak SBK'ya yönelik alan bilgisi ile öğretim programı bilgisinin ön planda olduğu, bunlara ek olarak öğretim stratejileri ve değerlendirme bilgisine yer verildiği dikkat çekmektedir. Kitapta konu başlıkları sırasının, SBK'nın doğası ile epistemolojisinden, SBK öğretim stratejileri ve değerlendirilmesine doğru bir düzende yapılandırılması önerilebilir. Bu sıralamanın, konunun teorik bilgi aşamasından uygulama boyutuna geçişte, bölümler arası aşamalılık ve bütünlüğü koruma yönüyle önemli olacağı düşünülmektedir. Kitapta, SBK öğretiminde alternatif öğrenme ortamları ve yeni yaklaşımların tanıtılması ile SBK öğretimine yenilikçi bakış açısı oluşturulmaktadır. Teorik bilgiye ek olarak örnek ders planları ve etkinlikler sunan bu kitabın, uygulamada SBK öğretimine yönelik farkındalık kazandırması bakımından işlevsel olduğu düşünülmektedir. Kitabın bazı bölüm içeriklerinde, konu seçimi ve SBK temelli senaryo yazımlarında kullanılabilecek güncel veriler sunan, alana özgü web sayfaları ile film isimleri önerilmiştir. Ayrıca okuyucular için, yeni araştırmalara 1şık tutan, fen öğretiminde etkileşimli SBK uygulamaları ile ilgili önerilerde bulunulmuştur. Bu yönüyle kitap, yerel/bölgesel, ulusal ve global boyutta vuku bulan güncel sosyobilimsel konuları teoride ve gerçek sınıf ortamında etkin öğrenme-öğretme yetisi kazandırma ve yapılacak araştırmalara yön verme bakımından rehber bir kaynak niteliği taşımaktadır. Nitekim kitabın amacı, kapsamı, 
alana katkısı ile önemi editör tarafından kitabın önsöz bölümünde ve arka kapağında ifade edilmiştir. Buna göre kitap, "sosyobilimsel konuların teorik alt yapısı ile birlikte örnek uygulamalar ortaya koymak, böylece fen ögretimi gerçekleştiren paydaşlara destek olmak" amacıyla hazırlanmıştır. Kitabın genişletilmiş basımı için SBK öğretimine özgü pedagojik alan bilgisi bileşenleri kapsamında yeni bölüm başlıkları eklenerek kitabın zenginleştirilmesi önerilebilir. Ayrıca, uzaktan eğitim süreci ile uyumlu, farklı eğitim kademelerinde SBK'ya özgü dijital eğitim materyallerinin geliştirilmesi üzerine yeni bölümler eklenebilir. Bununla birlikte sosyal bilimlere entegre edilerek tasarlanan SBK etkinliklerine yer verilmesi ile kitabın disiplinler üstü nitelik kazanacağı düşünülmektedir.

Yazar Katkıları

Giriş, kaynaklar, yazma ve taslak hazırlama, yazma, inceleme ve düzenleme, K.B. Yazar kitap incelemesi çalışmasının yayınlanmış halini okudu ve kabul etti.

\section{Yayın Etiği}

Kitap incelemesi türündeki bu çalışma, etik kurul izni gerektirmemektedir. 


\section{ORCID}

Kadriye Bayram (D) http://orcid.org/0000-0002-5366-0833

\section{Kaynakça}

Aydın, E., \& Kılıç Mocan, D. (2019). Türkiye'de dünden bugüne sosyobilimsel konular: Bir doküman analizi. Anadolu Öğretmen Dergisi, 3(2), 184-197.

Evren Yapıcıŏlu, A. (2020). Fen eğitiminde sosyobilimsel konu olarak covid 19 pandemisi ve örnek uygulama önerileri. Milli Eğitim Dergisi, 49(1), 1121-1141.

Genç, M. (2020). Kuramdan uygulamaya sosyobilimsel konular. Nobel Akademik.

Ke, L., Sadler, T. D., Zangori, L., \& Friedrichsen, P. J. (2020). Students' perceptions of socio-scientific issue-based learning and their appropriation of epistemic tools for systems thinking. International Journal of Science Education, 42(8), 13391361.

Kutluca, A. Y. (2012). Fen ve teknoloji ögretmen adaylarının klonlamaya ilişkin bilimsel ve sosyobilimsel argümantasyon kalitelerinin alan bilgisi yönünden incelenmesi. [Yüksek Lisans Tezi, Abant İzzet Baysal Üniversitesi].

Küçükaydın, M. A., \& Uluçınar Sağır, Ş. (2016). Kitap incelemesi: Understanding and developing science teachers' pedagogical content knowledge/John Loughran, Amanda Berry, Pamela Mulhall, 2012. İlköğretim Online, 15(1), 3-6.

Nasır, S. (2011). Kitap değerlendirmesi: Türkiye'de yükseköğretim: Karşılaştırmalı bir analiz/BS Gür, T. Küçükcan, 2009. Yüksekögretim Dergisi, 1(1), 54-55.

Özgün, B. B., \& Özgün, V. (2019). Kitap incelemesi: Kuramdan uygulamaya STEM $+\mathrm{+}$ eğitimi/Salih Çepni, 2017. Balıkesir Üniversitesi Sosyal Bilimler Enstitüsü Dergisi, 22(42), 429-438.

Sadler, T. D. (2004). Informal reasoning regarding socioscientific issues: A critical review of research. Journal of Research in Science Teaching, 41(5), 513-536.

Sadler, T. D. (2011). Situating socio-scientific issues in classrooms as a means of achieving goals of science education. T.D. Sadler (Ed.). Socio-scientific issues in the classroom: Teaching, learning and research içinde (s. 1-9). Springer.

Sadler, T. D., \& Zeidler, D. L. (2004), The morality of socioscientific issues: Construal and resolution of genetic engineering dilemmas. Science Education, 88, 4-27.

Sadler, T. D., \& Zeidler, D. L. (2005). The significance of content knowledge for informal reasoning regarding socioscientific issues: Applying genetics knowledge to genetic engineering issues. Science education, 89(1), 71-93.

Saruç, N. T. (2018). Kitap değerlendirmesi: Üniversitelerde strateji geliştirme sürecinde uygulamalı durum analizleri/Refika Bakoğlu, Müge Leyla Yıldız, 2016. Yükseköğretim Dergisi, 8(1), 124.

Yaman, İ. (2018). Kitap değerlendirmesi: Hayallerindeki eğitim fakültesi/Mustafa Zülküf Altan, 2017. Yükseköğretim Dergisi, 8(3), 368-369.

Zeidler, D. L. (2014). Socioscientific issues as a curriculum emphasis: Theory, research, and practice. N.G. Lederman \& S.K. Abell (Eds.), Handbook of research on science education içinde, 2, (s. 697-726).

Zeidler, D. L., Herman, B. C., \& Sadler, T. D. (2019). New directions in socioscientific issues research. Disciplinary and Interdisciplinary Science Education Research, 1(1), 1-9. 


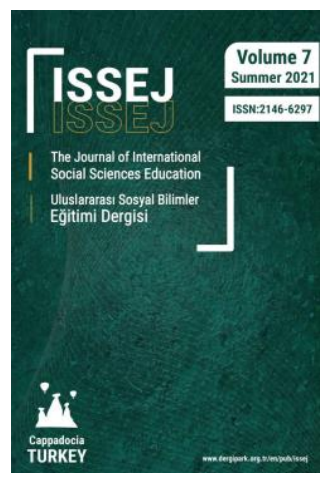

\section{Journal of International Social Science Education}

ISSN: 2146-6297 (Online) Journal homepage: https://www.dergipark.org.tr/en/pub/issej

\section{Book review: Socioscientific issues from theory to practice}

\section{Kadriye Bayram}

To cite this article: Bayram, K. (2021). Book review: Socioscientific issues from theory to practice, The Journal of International Social Science Education, 7(1), 200-218. DOI: 10.47615/issej.915640

To link to this article:https://doi.org/10.47615/issej.915640

(C) 2021 The Author(s). Reprints and permissions:

Authors have permission to share their article after it has been published in ISSEJ/The journal of International Social Science Education, either in print or online as a First Edition

ISSEJ/The Journal of International Social Science Education is a double peer-reviewed online journal. This article can be used for research, teaching and private studies. Only the authors are responsible for the content of the article. The journal has the copyright of the articles. The publisher cannot be held liable for any loss, transaction, claim or damage arising directly or indirectly in connection with the use of the research material.

All authors are requested to disclose any actual or potential conflict of interest including any financial, personal or other relationships with other people or organizations regarding the submitted work. 
Ә OPEN ACCESS (A) Check for updates

\section{Book review: Socioscientific issues from theory to practice}

\section{Kadriye Bayram}

Faculty of Education, Hacı Bektaş Veli University, Nevşehir, 50300 Turkey

\section{ABSTRACT}

Socioscientific issues (SSI) that play a role in the development of twentyfirst-century skills are directly included in the renewed science curriculum and science teacher training program in Turkey. Considering the SSl' potential contribution to the development of functional scientific literacy and high-level knowledge and skills, SSI' effective integration process in education is important in theory and practice. Therefore, the book titled "Socioscientific Issues from Theory to Practice" which is structured on teaching SSI and the place of SSI in science education was reviewed in this study in terms of content, scope, contribution to the field and suggestions. This book is prepared under the editorship of Assoc. Prof. Murat Genç and published in print and as an e-book. The target audience of the book consists of teachers, prospective and pre-service teachers, academicians and researchers in the field of science teaching. The chapter contents of the book provide the reader with opportunities of supporting, experiencing science education and providing a new point of view in the context of SSI with recommendations and activity examples developed for SSI teaching in class and out-of-school learning environments. It provides not only obtaining theoretical scientific knowledge about SSI but also implementing it. In the new publication of the book, it can be suggested that the book may be enriched by adding new chapter titles, such as "pedagogical content knowledge towards SSI SSI teaching specific to different disciplines and development of digital learning materials for SSI".

CONTACT Kadriye Bayram $\otimes$ k.bayram@yahoo.com

(C) 2021 The Author(s). Kadiye Bayram

This is an Open Access article distributed under the terms of the Creative Commons Attribution-NonCommercial License (http://creativecommons.org/licenses/by-nc/4.0), which permits use, distribution and reproduction in any medium, provided the original work is properly cited and is not used for commercial purposes. 


\title{
Book review
}

\author{
Book Review: Socioscientific issues from theory to practice \\ Editor: Assoc. Prof. Murat GENÇ \\ Publisher: Nobel \\ Printing: May, 2020 \\ Number of pages: 440
}

ISBN: 978-625-402-058-2

The book titled "Socioscientific Issues from Theory to Practice", published in print and as an e-book, consists of xviii+422 pages and 16 chapters under the editorship of Assoc. Prof. Murat GENÇ. The target audience of the book consists of teachers, prospective and pre-service teachers, academicians and researchers in the field of sciences. The chapter contents of the book have been structured by 20 academicians who are experts in their field. It is worth noting that the content has been created in a "spiral structure" and with an interdisciplinary point of view. It is understood that this book has the quality of providing the continuity of the other national books published on SSI. Also, in this book, the scope of the topic has been diversified, alternative and additional titles have been discussed, and with several activity examples, the reflections of the theoretical topic in practice have been examined in a more detailed and in-depth manner. Based on their topics, the chapter titles of the book in English are as follows: "The relationship between socioscientific issues (SSI) and science-attitude, Nature of SSI and its place in science education, Science instruction and assessment with SSI, SSI selection and examples of current dilemmas, SSI and instruction strategies, SSI and argumentation, The SEE-SEP model in SSI instruction, Reasoning in SSI, Assessment of socioscientific reasoning, SSI and reasoning for question generation, The role of media in SSI instruction, Ethics in SSI, SSI and out-of-school learning environments, Epistemological beliefs and SSI, Teacher roles and mentorship in SSI instruction, and SSI and STEM education."

Each chapter that has been written in a clear and comprehensible academic language has been handled in the context of SSI. Firstly, targeted chapter outcomes have been specified in relation to the content. Afterwards, by introducing the general framework of the content, its detailed conceptual structure has been described, and content-related variables have been explained in-depth with the support of the literature. Topic-specific representations have been used with tables, models and figures. Following this, SSIspecific activity examples compatible with the content outcomes have been presented. In addition to this, based on the literature review, critical cases that are open to criticism and inquiry due to the nature of the topic have been emphasized. And conclusionsinferences on the content have been made. At the end of the chapter, chapter assessment questions consisting of open-ended and multiple-choice items have been included. In this context, the review report for each part of the book is given below.

The first chapter is written by the editor. In this section, the relationship between SSI and science-attitude-scientific literacy is examined. In the content, the conceptual framework and definition of SSI are laid out, and global-scale SSI examples that are frequently on the agenda are included. The concepts of attitude and scientific attitude are discussed. It 
is shown on figures that relationship of attitude with knowledge, belief, values and worldview. The six dimensions and three components of scientific attitude, and the characteristics of a person with a scientific attitude are included. Afterwards, the "science, attitude, technology and society" effect is mentioned over decision-making on SSI that are included in our daily lives to a broad extent from global dilemmatic issues to local/regional issues. At the same time, an emphasis is made on the effects of various factors on the affective, social, cognitive development and reasoning-decision-making capacity with the SSI-assisted learning environment. In this context, it is recommended to support the education processes of students with different levels of scientific attitudes with SSI.

The 2nd chapter is structured around the themes of "the nature of SSI, SSI characteristics and examples, its historical process, its place in the science curriculum in the world and in Turkey, importance of SSI instruction and basic science goals/outcomes associated with SSI". In the first part, how socially controversial issues come into the agenda is emphasized, and the definitions and properties of SSI from the literature are included. Factors affecting the decision-making process regarding SSI are presented. In the context of the historical development of SSI instruction, different science curriculum approaches followed in the world are examined with a critical perspective with their positive aspects and shortcomings. The characteristics of SSI instruction that are different from the science-technology-society (STS) and science-technology-society-environment (STSE) approaches are mentioned. The requirements of SSI instruction are specified. In this context, research results examining SSI-based science instruction and "scientific literacy, understanding of nature of science, reasoning skills, science content knowledge" are included. Moreover, differences among types of reasoning are shown over a model. Additionally, the place and importance of SSI in the science, physics, chemistry and biology curricula in Turkey are historically investigated. Similarly, the integration process of SSI into curricula in countries in the world is explained. Attention is driven towards the importance of different variables in the effective use of SSI in the curriculum. After this, an example activity plan for SSI instruction is included.

The 3rd chapter starting with the definition of SSI mentions the reasons why SSI are debatable and complex. Based on this, it is emphasized that it needs to be used in science instruction as it provides various opportunities. The integration of SSI into education is explained by its targeted outcomes in the science, physics and biology curricula. The criteria for a topic to be determined as an SSI and SSI sources are presented. Steps to be followed in the classroom environment in the context of SSI for science instruction are specified. It is emphasized that SSI on a local and global level should be integrated into the instruction process in a balanced manner. In this context, the characteristics of SSI materials, teacher-student interaction influential on instruction outputs and the roles of the teacher in the process are shortly mentioned. An activity of exemplary instruction construction based on the $5 \mathrm{E}$ instruction model on the topic of Human and the Environment is presented. Afterwards, activities and types of assessment providing opportunities of using what is learned before, during and after SSI-based science instruction in daily life, are recommended. Difficulties in measurement-assessment of SSI-based knowledge and skills are pointed out. It is explained with examples from the literature that SSI-based conceptual learning levels, scientific thinking and decision- 
making skills and understanding of the nature of science are assessed with different measurement instruments.

The 4th chapter includes ways of selecting SSI among the specific purposes of the science curriculum (2018), SSI scenario-writing and examples of socioscientific dilemmas. First of all, for topic selection, SSI and their characteristics are defined. Local, national and global SSI examples that are frequently studied in the literature in the field of science education are included. The place of these issues in the curriculum and the contents-concepts that SSIs are related to are explained in detail. In the scope of this process, the scientific context, target system and contents of some SSI examples integrated into the program are summarized on figures. Selection of a suitable SSI is shown with a schema. Various criteria that are overlapping with each other which have been recommended by different researchers in SSI assessment are presented. In this chapter, additionally, issues that need to be paid attention to in the SSI scenario-writing process are mentioned. The author of the chapter also proposes that unit designs may be carried out on different SSI.

The 5th chapter is structured on the content of instructional strategies in SSI. First of all, it is emphasized that instruction of SSI is important in development of cognitive, social, moral and emotional skills. An emphasis is made on skills that need to be primarily provided in SSI. The importance of instructional strategies is focused on in learning SSI whose place is outlined in the curricula of the Turkish Ministry of National Education (MNE). In this context, it is specified that various methods are used in SSI activities, and the suitability of such methods is discussed. Additionally, SSI instruction models included in the literature are explained. Based on this, it is emphasized that utilization of the appropriate tools, methods and techniques in SSI instruction is effective on learning outputs. Example activities where different methods oriented the topic are used are included. A pedagogic model proposed for SSI in the literature is explained. After this, issues to be paid attention to for the use of different strategies in SSI instruction are specified. The process of forming a lesson with socioscientific contents is presented in items, and a detailed activity plan on the topic of "nutrition" is provided.

The 6th chapter is structured on the theme of argumentation in SSI. In the chapter, first of all, SSI-based instruction for development of high-level skills is emphasized. Differences between "the SSI approach and inquiry-based approach" are mentioned, and they are exemplified by the topic of GMOs. The difference between "decision-making and idea development" in terms of participation status and display of behaviors is explained, and it is exemplified by the topics of "water resources and deforestation". The roles of teachers in development of various skills with SSI-based instruction are discussed. In this context, argument models that are frequently utilized in the literature are introduced, and examples of application are included. After this, the difference between the concepts of "scientific explanation" and "argumentation" is focused on via the topic of climate change. Argumentation techniques are introduced, and each technique is exemplified with science topics. Finally, assessment process of argumentation skills is included. A text, evidence-based assessment schema and rubric developed for SSI-specific, are introduced from the literature. The author of the chapter 
proposes that such instruction and measurement instruments may be used for different SSI.

Following a detailed introduction of SSI and their content, the development of decisionmaking skills in SSI and the SEE-SEP model in the analysis of the decision-making process are introduced over examples in the 7th chapter. The SEE-SEP model and the interaction of different disciplines and dimensions in the model are demonstrated with two different figures. The usage areas of this model in the literature are specified. With this model, the comprehensive inclusion of six disciplines in the SSI decision-making process and that these disciplines are in interaction with three different dimensions are described. Interactions occurring in the model are shown on a table with example socioscientific claims, and explained with exampled scenarios. From here, it is concluded that the context SSI influences the direction of the interaction, and this is demonstrated over examples. In this chapter, the importance of conscious decisionmaking skills in SSI for argumentation and scientific literacy is emphasized. The author demonstrates the application of a scenario-assisted instruction plan with an example for developing the decision-making skills of pre-service teachers on the genetics topic and determining the factors affecting the process.

In the 8th chapter, various "reasoning" processes and SSI-based science instruction are included. The types of "reasoning" which is defined in the literature are explained, and it is stated that it is affected by cognitive, affective and social factors. Various reasoning patterns in SSI from the literature are demonstrated on figure. It is explained through examples that patterns may change according to the content and the context. Additionally, by making a definition of socioscientific reasoning, the dimensions of socioscientific reasoning are explained over various topics. In addition to these, it is emphasized that developing the skills of reasoning is important in training science literate individuals. The increase in the importance paid to reasoning processes with the new classes added to the undergraduate programs on Science Education is assessed. Factors effective on a successful reasoning process and SSI-based instruction are outlined. At the end of the chapter, an example application activity on the topic of organ transplantation that could be used in science lesson is provided.

The 9th chapter includes different approaches to assessment of socioscientific reasoning and theoretical-practical information on measurement instruments. Frequently emphasized themes in socioscientific reasoning researches are stated. Qualitative and quantitative measurement tools that have been used at different levels from the past to the present to assess the skills of socioscientific reasoning are included. Furthermore, by showing examples from the literature, it is emphasized that the forms of measurement tools that are adapted for different issues may be utilized. For a more in-depth assessment of socioscientific reasoning, it is shown with an example from the literature that alternative assessment is achieved by combining two different measurement instruments. In the following step, the positive and negative aspects of assessing socioscientific reasoning with the quantitative and qualitative approaches are explained. Recommendations are provided to overcome the shortcomings of assessment approaches. Based on the examples given in the scope of the chapter, it is recommended to examine the variable of socioscientific reasoning in the framework of SSI instruction. 
In the 10th chapter, the heading of "the reasoning for question forming towards SSI for high-level thinking" is discussed. First of all, the characteristics of a structured classroom environment proposed by Vygotsky in the educational context with the sociocultural learning theory are introduced. After this, the differences between dialogic instruction and the traditional monologic method are discussed in this chapter. The importance of question forming and question asking skills is emphasized based on the difficulty of having dialogic instruction in every content. Additionally, factors affecting question quality and asking questions are listed. In this context, the importance of in-depth questions supporting high-level thinking and reasoning skills is emphasized. With examples, attention has been drawn to reasoning models in education from low-level to advanced-level. Studies from the literature examining the development of the pedagogical content knowledge of teachers on asking questions and dialogue are included. Furthermore, this chapter also mentions factors affecting production of questions, as well as ways of forming questions. The effects of text/scenario-based question forming on various student capacities are stated. At the end of this chapter on development of these capacities, an example of an activity of argumentation-based deep question forming in SSI instruction is presented.

The 11th chapter is structured under the title of "the role of the media in SSI instruction". In the introduction, it is emphasized that SSI contents that concern science and society have been included more in the media in recent years. In this context, an emphasis is made on the concepts of media and scientific literacy at the same time. A definition of SSI is made. Then, the transition process from the science-technology-society (STS) approach to the socioscientific situation-based instruction approach is explained with the targeted SSI outcomes in the science curricula from the past to the present. Therefore, the importance of SSI for science education and the society is included. The SEE-SEP model which shows that the six subject areas of SSI are related to three components is explained as the "SSI construct" in this chapter. Differences between science subjects and socioscientific issues are mentioned in terms of problem-solving methods and clear scientific explanations. By pointing out SSI characteristics and the media among SSI information sources, the topic of media is discussed in detail. First of all, a definition of media is included, and types of media are specified in terms of their interaction characteristics. After this, the role of the media in achieving information flow, its effect on the thought structure of individuals and its relationship to science and society are explained. Moreover, based on the importance of conscious media usage; media literacy, history, its place in curricula and skills and values that it provides to the individual are included. An emphasis is then made on the issues of the quality of science news on SSI on the media, its content and how it needs to be read. The importance of the media in SSI instruction as an educational tool is focused on. Accordingly, it is proposed that it is needed to achieve the integration of media literacy content and SSI education.

The 12th chapter is structured in the context of ethics and morality in SSI. In the introduction, the main goal of science literacy, its functional level and the importance of ethics and moral inquiries are mentioned. The socioscientific elements of functional science literacy are shown on a model from the literature. It is concluded that SSI instruction carried out with an ethics aspect has positive effects on different variables, such as moral reasoning, social/emotional/psychological development, meaningful 
learning etc. The chapter also includes the themes of the concept of ethics, types of ethics, differences between ethics and morality, ethical justification, moral judgement development and ethics education. Firstly, under the discipline of philosophy of morals, the origin of the term "ethics" is examined, and its definition is made. The objectives and main problems of ethics are discussed. The origins of the concepts of morality and ethics are investigated, their definitions are made comparatively, and their difference is specified by support from the literature. Types of ethics are explained, and their various study areas are included. The author explains for which problems these types of ethics provide solution recommendations. In addition to this, the differences of types of ethics are discussed in terms of context, an interdisciplinary holistic approach and case research. Various forms of argumentation justifying the rightfulness of judgments in ethics are included. Moral judgment and moral development are explained based on various theories. The importance of "ethics education" and "SSI in ethics education" for development of various skills in the context of ethics and morality is emphasized. Within the scope of ethics education in SSI, assessment tools unique to specific developmental fields are included.

The 13th chapter is structured around the content of SSI and out-of-school learning environments. In the chapter, the importance of alternative learning environments in realization of skill-knowledge acquisition and scientific literacy is emphasized. Additionally, with the example activities provided, an emphasis is made on the effectiveness of different out-of-school learning environments in the process of SSI instruction. In the introduction, the concept of scientific literacy and its sub-dimensions are mentioned. After this, with a bibliometric analysis on SSI, it is recommended to conduct studies on SSI integrated into out-of-school learning environments. SSI researches conducted in out-of-school learning environments and variables that have been examined in the literature are given as examples. Examples are provided for field trips among out-of-school learning environments. These examples include a field trip activity example on the topic of using chemicals in agriculture. Science centers as another out-of-school learning environment and their role in SSI instruction are included. In this context, an activity example on the topic of Energy Resources is provided.

In the introduction of the 14th chapter, based on the vision of scientific literacy, the necessity of SSI is emphasized. The concept of "epistemological beliefs" is then introduced. From the literature, answers based on different approaches towards the problems of the information theory and views on epistemology are explained. The characteristics of beliefs and epistemological beliefs are specified. Epistemological belief models are explained with different approaches. Inferences are made from the results of research conducted on epistemological belief and SSI. The nature of epistemological belief and SSI is comparatively explained. Based on this, the approaches of students with different epistemological beliefs to various SSI are examined through examples. The points of view of individuals with different epistemological beliefs towards SSI are described with the "cognitive processing model". At the end of the chapter, the specific goals of SSI in the science curriculum (2018) are included, and recommendations are provided to teachers in realization of these goals. 
The 15th chapter is constructed on the title of teacher roles and mentorship in SSI instruction. The chapter includes that themes of the roles of teachers in SSI instruction, factors affecting SSI instruction and the role of the professional development of the teacher towards SSI and mentorship. From the literature, SSI-related student outcomes are specified. Based on studies examining the effectiveness of SSI, it is emphasized that it is aimed to train scientific literate individuals. The author mentions the reasons for the limited use of SSI in the classroom environment despite the fact that it is included in science curricula in Turkey. In this context, teacher qualifications in the framework of SSI instruction are pointed out. At the same time, the SSI-related profiles of teachers are explained. In this chapter, additionally, emotional characteristics affecting SSI instruction are listed. Under another title on factors influential on SSI instruction, the content and pedagogical content knowledge of the teacher is explained. In this context, difficulties experienced by teachers in the practice of SSI-based instruction are discussed. Various recommendations are made for overcoming difficulties experienced in the SSI instruction process. Based on the conclusion that the role of the teacher in SSI instruction is affected by their professional development level, it is recommended to directly integrate controversial topics into curricula for professional development in terms of SSI. It is recommended to plan mentorship programs based on the difficulties encountered by the teacher and their needs. It is emphasized that, with mentorship support, a positive contribution will be made to the school and students in addition to teacher qualifications.

In the last chapter of the book, the SSI-based instruction approach and the STEM education approach are discussed. The authors of the chapter, who provide a descriptive conceptual framework on STEM education, mention the components of STEM literacy and scientific literacy based on the objective of science education. And they portray the difference between these two concepts. The requirements of a STEM education reform are emphasized. The framework of STEM integration in K-12 education is presented over a model from the literature. In this framework, 21 st century skills supportive of STEM literacy are described. It is pointed out that the approaches that are used in the integration of STEM and STEAM education into curricula are different. The emergence of STEM education in the world and its requirements are explained. Detailed criticisms in the field regarding STEM education are included. In the frame of these criticisms that are open to improvement in STEM education, the importance of integrating SSI into STEM education is emphasized. At the end of the chapter, the authors present an example activity where an SSI with a regional character specific to Turkey is integrated into STEM education and implemented.

Almost all chapters in the book make an emphasis on the themes of "the scope of SSI, its relationship to science-technology-society, its place in science education, SSI instruction, scientific literacy, its relationship to high-level thinking, reasoning and decision-making skills, and ethics." In the book, it gets attention that SSI-related content and curriculum knowledge are prominent, in addition these, instructional strategies and assessment knowledge are included in compatibility with pedagogical content knowledge (PCK) components. The book has importance in terms of forming an innovative point of view towards SSI instruction by introduction of alternative SSI-learning environments and approaches. It is believed that the book is useful in terms of raising awareness of SSI 
instruction in practice with exemplary activities and lesson plans in addition to theoretical information. For readers, recommendations that shed light on new research on SSI applications in science instruction have been made. This book has the quality of being a reference book regarding provision of effective learning-teaching SSI capacities in theory and in an actual classroom environment. In summary, this book provides not only obtaining theoretical scientific knowledge but also implementing it. For a new publication of the book, the book may be enriched by adding new chapter titles in the scope of Pedagogical Content Knowledge components. Additionally, the reflections of digitalization on SSI instruction may be examined. Moreover, formation of the chapter titles by considering educational levels such as preschool, primary, secondary and high school, and development of additional SSI activities integrated into social sciences will increase the size of the target audience and potential of the book even further.

\section{Author Contributions}

Conceptualization, resources, writing-original draft preparation, writing-review and editing, K.B. The author has read and agreed to the published version of the manuscript.

\section{Publication Ethics}

The book review study hasn't been requiring ethics committee approval. 


\section{ORCID}

\section{Name Surname (1D http://orcid.org/0000-0002-5366-0833}

\section{References}

Aydın, E., \& Kılıç Mocan, D. (2019). Türkiye'de dünden bugüne sosyobilimsel konular: Bir doküman analizi. Anadolu Ögretmen Dergisi, 3(2), 184-197.

Evren Yapıcıŏlu, A. (2020). Fen eğitiminde sosyobilimsel konu olarak covid 19 pandemisi ve örnek uygulama önerileri. Milli Ĕ̈itim Dergisi, 49(1), 1121-1141.

Genç, M. (2020). Kuramdan uygulamaya sosyobilimsel konular. Nobel Akademik.

Ke, L., Sadler, T. D., Zangori, L., \& Friedrichsen, P. J. (2020). Students' perceptions of socioscientific issue-based learning and their appropriation of epistemic tools for systems thinking. International Journal of Science Education, 42(8), 1339-1361.

Kutluca, A. Y. (2012). Fen ve teknoloji ögretmen adaylarının klonlamaya ilişkin bilimsel ve sosyobilimsel argümantasyon kalitelerinin alan bilgisi yönünden incelenmesi. [Yüksek Lisans Tezi, Abant İzzet Baysal Üniversitesi].

Küçükaydın, M. A., \& Uluçınar Sağır, Ş. (2016). Kitap incelemesi: Understanding and developing science teachers' pedagogical content knowledge/John Loughran, Amanda Berry, Pamela Mulhall, 2012. İlkögretim Online, 15(1), 3-6.

Nasır, S. (2011). Kitap değerlendirmesi: Türkiye'de yükseköğretim: Karşılaştırmalı bir analiz/BS Gür, T. Küçükcan, 2009. Yükseköğretim Dergisi, 1(1), 54-55.

Özgün, B. B., \& Özgün, V. (2019). Kitap incelemesi: Kuramdan uygulamaya STEM $\mathrm{SH}_{+\mathrm{A}}^{+\mathrm{A}}$ eğitimi/Salih Çepni, 2017. Balıkesir Üniversitesi Sosyal Bilimler Enstitüsü Dergisi, 22(42), 429-438.

Sadler, T. D. (2004). Informal reasoning regarding socioscientific issues: A critical review of research. Journal of Research in Science Teaching, 41(5), 513-536.

Sadler, T. D. (2011). Situating socio-scientific issues in classrooms as a means of achieving goals of science education. T.D. Sadler (Ed.). Socio-scientific issues in the classroom: Teaching, learning and research içinde (s. 1-9). Springer.

Sadler, T. D., \& Zeidler, D. L. (2004), The morality of socioscientific issues: Construal and resolution of genetic engineering dilemmas. Science Education, 88, 4-27.

Sadler, T. D., \& Zeidler, D. L. (2005). The significance of content knowledge for informal reasoning regarding socioscientific issues: Applying genetics knowledge to genetic engineering issues. Science education, 89(1), 71-93.

Saruç, N. T. (2018). Kitap değerlendirmesi: Üniversitelerde strateji geliştirme sürecinde uygulamalı durum analizleri/Refika Bakoğlu, Müge Leyla Yıldız, 2016. Yükseköğretim Dergisi, 8(1), 124.

Yaman, İ. (2018). Kitap değerlendirmesi: Hayallerindeki eğitim fakültesi/Mustafa Zülküf Altan, 2017. Yüksekögrretim Dergisi, 8(3), 368-369.

Zeidler, D. L. (2014). Socioscientific issues as a curriculum emphasis: Theory, research, and practice. N.G. Lederman \& S.K. Abell (Eds.), Handbook of research on science education içinde, 2, (s. 697-726).

Zeidler, D. L., Herman, B. C., \& Sadler, T. D. (2019). New directions in socioscientific issues research. Disciplinary and Interdisciplinary Science Education Research, 1(1), 1-9. 